\title{
Khat use and monitoring drug use in Europe: The current situation and issues for the future
}

\author{
Paul Griffiths*, Dominique Lopez, Roumen Sedefov, Ana Gallegos, Brendan Hughes, \\ André Noor, Luis Royuela
}

European Monitoring Centre for Drugs and Drug Addiction (EMCDDA), Cais do Sodré, 1249-289 Lisbon, Portugal

\section{A R T I C L E I N F O}

\section{Article history:}

Received 20 January 2010

Received in revised form 2 March 2010

Accepted 26 April 2010

Available online 7 May 2010

\section{Keywords:}

Khat

Drug use

Europe

Cathine

Cathinone

Legislation

\begin{abstract}
A B S T R A C T
Aim of the study: To review the information available on the use of khat (Catha edulis) in the EU, and to assess the future use of this drug and related substances.

Material and methods: Khat is not controlled by international law and it has not been systematically included in the list of illicit drugs monitored in the EU. The current principal source of information on khat use in Europe is the early-warning system set up to monitor new and emerging drugs. Further information was obtained from official national reports to the EMCDDA and from the scientific literature. Results: Across Europe, the use of khat is low. Khat use is limited to countries with immigrant communities from countries where khat use is common (such as Ethiopia, Somalia and Kenya). Information on the prevalence of khat use in the general population is scarce. Data on seizures provide an insight on the situation, though these may be difficult to interpret. The most recent estimates suggest that Europe accounts for about $40 \%$ of the khat seized worldwide.

Conclusion: The shortage of data on the use and patterns of use of khat in Europe does not allow an evaluation of the needs for health and social interventions in communities in which the drug is used. But seizures of the plant are increasing in the $\mathrm{EU}$, and more synthetic derivatives of the pharmacologically active ingredients of the plant (cathine and cathinone) are appearing on the market. Some of these, like mephedrone, have significant potential for future diffusion, and are likely to play a greater role on the European drug scene of the future.
\end{abstract}

(c) 2010 Elsevier Ireland Ltd. All rights reserved.

\section{Introduction}

The Member States of the EU have made considerable progress in developing a common approach to monitoring patterns of illicit drug use, and this supports an increasingly consensus-driven drug policy debate (Bergeron and Griffiths, 2006). However, khat ${ }^{1}$ use sits awkwardly within the current reporting framework, and this hampers the production of a European-level analysis of the use of this drug. Why this is so, and what information is available at the

Abbreviations: ACMD, Advisory Council on Misuse of Drugs; CNS, central nervous system; EMCDDA, European Monitoring Centre for Drugs and Drug Addiction; EU, European Union; EWS, early-warning system; RCMP, Royal Canadian Mounted Police; UN, United Nations; UNODC, United Nations Office on Drugs and Crime; UK, United Kingdom; WHO, World Health Organisation.

* Corresponding author. Tel.: +351 2112102 06; fax: +351 213584441 .

E-mail addresses: dominique.lopez@emcdda.europa.eu, paul.griffiths@emcdda.europa.eu (P. Griffiths).

${ }^{1}$ Khat is a herbal product consisting of the leaves and shoots of the shrub Catha edulis (from the Celastraceae family). There are many different varieties of Catha edulis depending upon the area in which it is cultivated (ACMD, 2005). In the rest of this text the khat plants (Catha edulis) will be referred as khat.
European level, are the topics addressed in this paper. The analysis is extended to consider if the current evidence suggests that this drug, or synthetic variations of the psychoactive compounds it contains, are likely to play a greater role in the European drug scene of the future.

\section{Khat and the European reporting framework}

The European Monitoring Centre for Drugs and Drug Addiction (EMCDDA), a decentralised technical agency of the European Union, is tasked with acting as a drug information hub for Europe. Its mission is to work closely with Member States to provide factual, objective, reliable and comparable information on the drug phenomenon. The agency commenced its monitoring activities around 1995, and today 30 countries - the 27 EU Member States, Norway, Turkey and Croatia - participate in the system, providing information on drug use, its consequences and political and legal developments (EMCDDA, 2009a).

At the European level, khat has historically fallen into a grey area for drug monitoring and to a large extent the use of the substance has been ignored. There are a number of reasons for this. First, there 


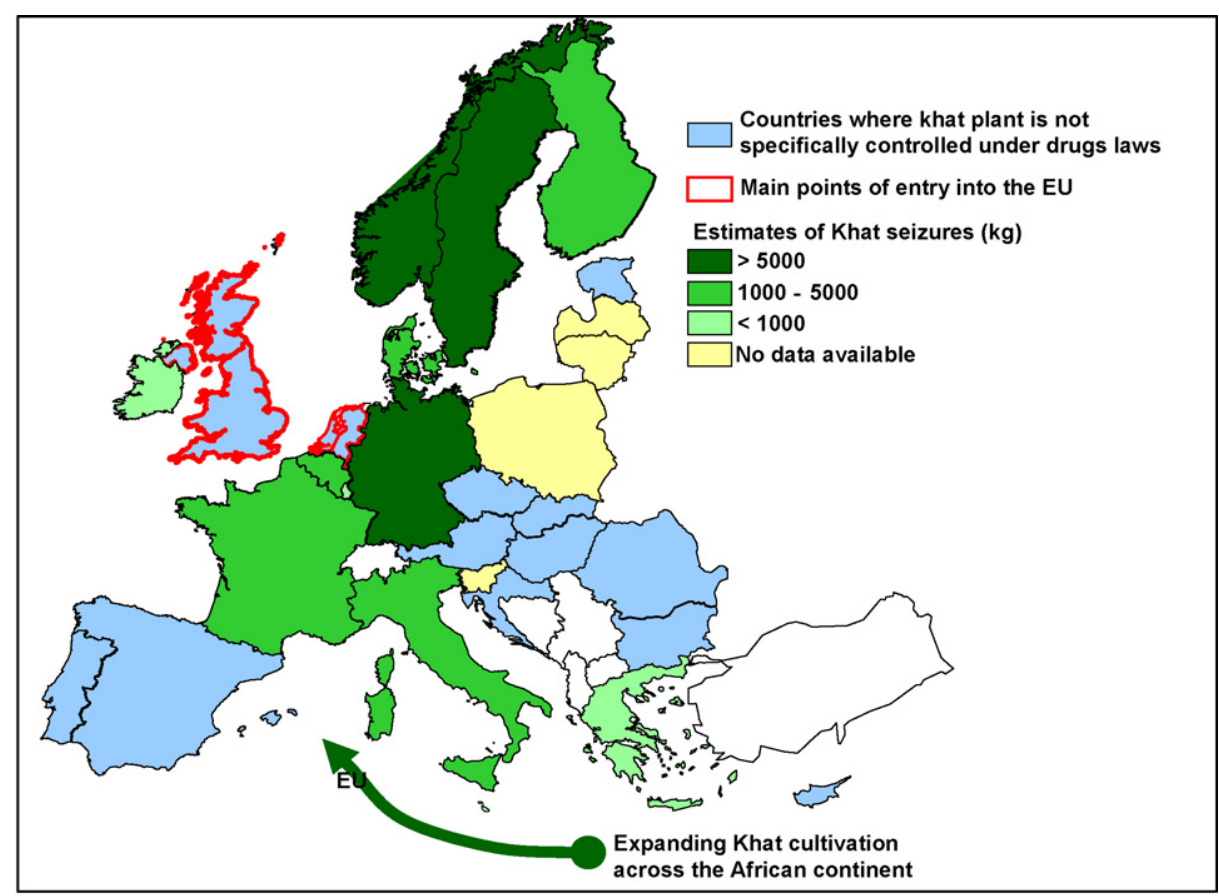

Source: EMCDDA (2009c).

Fig. 1. Countries among EU Member States and Norway not specifically controlling khat under drugs laws, and estimates of khat seizures. Source: EMCDDA (2009c).

is considerable political sensitivity concerning subsidiarity, as well as on the regulatory distinction between legitimate trade goods, medicines and controlled substances. The status of khat under the international drug control conventions, together with its varied legal status within the EU, means that no clear remit exits for the monitoring of this product within the drug control framework. Second, for practical, methodological and political reasons, data on khat consumption are largely lacking at the European level. The available information indicates that across Europe as a whole, the use of khat is low and is largely restricted to countries with specific immigrant populations. Correspondingly, khat use is not included in most quantitative data collection exercises, either because of questions of relevance or simply the methodological difficulties in surveying the target communities. Even where significant khatconsuming communities exist, the methodological difficulties in monitoring drug use among ethnic minorities and immigrant populations mean that data are only available from a few countries who have invested in research studies in this area. Moreover, registry data from drug services are also largely unavailable, either because services for ethnic minority and immigrant drug users are poorly developed in most countries, or because of the sensitivity of reporting on the ethnicity of service users. Where studies of drug use among minority populations do exist, the common use of qualitative methods, with the results often being unavailable in referenced sources, limits their contribution to monitoring at European level.

The monitoring of drug use among immigrant and ethnic groups is also politically sensitive in many parts of Europe, and this has hindered the development of a common conceptual framework for reporting on this issue. In most countries, immigrant groups that are not officially registered with the authorities are largely invisible for official reporting purposes and authorities may sometimes not even wish to officially acknowledge their possible existence. Some countries also have legal restrictions on reporting on ethnicity. In general, there are also concerns that focusing on the drug use of such groups can perpetuate negative stereotypes and thereby encourage stigmatism and racism. This is complicated by some ethnic minorities groups being particularly associated with the traf- ficking or supply of drugs in parts of Europe (EMCDDA, 2008). It is not the purpose of this paper to elaborate these issues, but taken together they have acted as a brake on the development of drug use monitoring among minority populations at a European level, and as such add to the difficulties of reporting on khat use in the EU.

Despite these difficulties, some research studies are available from a few European countries, most notably the UK. A number of countries also include data on khat seizures in their reports to either the EMCDDA or the United Nations Office on Drugs and Crime (UNODC). The EMCDDA also collates other information on khat that emerges through the annual reporting of national focal points on their drug situation. This provides a crude, partial overview, although some areas, such as the legal status of the drug in different jurisdictions, are relatively well elaborated. In addition, case reports on both khat, and synthetic cathinones are received through the European early-warning system (EWS) on new psychoactive substances (EMCDDA, 2007). This is an event driven mechanism designed to identify new compounds that are uncontrolled but which may pose a similar threat to those substances listed under the international drug control conventions. Although only limited information on khat has been reported to the EWS, there is a growing number of reports on the availability of synthetic psychoactive compounds derived from those naturally occurring in khat, and these largely uncontrolled synthetic cathinones may play a more prominent role in Europe's recreational drug scene in the future.

Taken together, the information available on khat consumption in the EU is both partial and weak. However, it does permit a cautious and general analysis to be made on the current situation in Europe and allows some speculation on future issues that are likely to be important.

\section{Legal situation of khat in Europe}

In the EU, the starting point for controlling psychoactive substances is the two UN treaties, the Single Convention on Narcotic Drugs of 1961 and the Convention on Psychotropic Substances of 1971 , which between them list nearly 250 substances to be con- 
trolled by all signatories under their national drug legislation. The psychoactive substances in khat, cathine and cathinone, are listed in Schedule III and Schedule I respectively of the 1971 convention; it follows that they are also therefore controlled in all EU Member States.

The plant khat is not controlled at UN level. In 2006, the WHO Expert Committee on Drug Dependence critically reviewed khat and recommended not to schedule it in the UN conventions, since the level of abuse and threat to public health was not significant enough to warrant international control (WHO Expert Committee on Drug Dependence, 2006).

Nevertheless, countries may still opt to control substances under national legislation, and 13 EU Member States and Norway report having added the plant to their lists of controlled substances ${ }^{2}$ (Fig. 1) (EMCDDA, 2009b). In the majority of the EU Member States and Norway, the law officially does not recognise differences between drugs, and drugs offences may incur the same penalty regardless of the substances involved. Of these 14 countries, Belgium and Ireland have more lenient penalties only for personal possession of cannabis, while in Latvia the maximum sentence is higher for trafficking in "especially dangerous" drugs. Otherwise, penalties for possession or trafficking of khat are theoretically equal to those for heroin (EMCDDA, 2009b).

For the remaining countries in the EU the issue has the possibility to be a legal grey area, in a parallel to mushrooms containing the controlled substances psilocin and/or psilocybin. If controlled substances occur in a plant, is the plant itself subject to the same level of control as the substances, or not? A number of national legal experts, when questioned, stated that the khat plant itself was effectively under control in their country by virtue of its active ingredients. In others, it may depend on various legal definitions, such as 'preparations' or 'mixtures'. In the same way that dried mushrooms, or those wrapped for sale, were sometimes considered 'preparations', it would be a matter for domestic courts to decide whether or not cut bundles of khat leaves could be considered 'preparations' of cathine or cathinone under national law. This lack of legal clarity and possibly the relative unfamiliarity that some countries may have with khat can be reflected in the enforcement actions. For example, seizures of khat have been reported by Luxembourg, Hungary and Malta even though these countries do not appear to specifically control khat in their drug laws. Similarly, Spain reports khat seizures in 2008, whereas the regulations establishing the legal control of the substance have not yet been signed into law. It should be noted however, that seizures by law enforcement authorities can occur in various legal contexts, for example in the presence of other substances, criminal activities or contraband goods.

Control under medicines legislation may also be possible; the second part of the EU-wide definition of a medicine is 'Any substance or combination of substances which may be used in or administered to human beings either with a view to restoring, correcting or modifying physiological functions by exerting a pharmacological, immunological or metabolic action, or to making a medical diagnosis'. ${ }^{3}$ While the EMCDDA does not have a comprehensive overview of national medicines laws and the substances licensed for domestic marketing as medicinal products, two examples have come to light. In Germany, preparations of cathine containing up to $5 \%$ as solution (maximum dose $1600 \mathrm{mg}$ per packaging unit) without any other narcotic substances or per unit dose up to $40 \mathrm{mg}$ cathine, calculated as base, are exempted from special prescription and may be prescribed by 'normal' medical prescrip-

\footnotetext{
2 Belgium, Denmark, Germany, Finland, France, Greece, Ireland, Italy, Latvia, Lithuania, Norway, Poland, Slovenia and Sweden.

3 Directive 2001/83/EC, Art.1(b).
}

tion. In the UK, khat is licensed as a medicinal product under the Medicines Act 1968, but to date it has never been imported as a medicinal product - though it can also be imported to the UK legally when declared as a vegetable (ACMD, 2005).

None of the 14 European countries that control the plant as an illicit drug make legal distinctions between controlled substances based on their potential harmfulness (such distinctions do exist in a few European countries, such as Cyprus, the Netherlands, Romania, the UK). Nevertheless, guidance to criminal justice officials as to what constitutes the acceptable limit for personal use can provide an interesting proxy. In Norway, a circular from the Director General of Public Prosecutions ${ }^{4}$ prescribes a 'minor' fine for possession if the quantity does not exceed $0.5 \mathrm{~g}$ of heroin or cocaine, $15 \mathrm{~g}$ of cannabis, or $5 \mathrm{~kg}$ of khat. In Denmark, a similar notice ${ }^{5}$ considers personal use thresholds as $10 \mathrm{~g}$ of cannabis resin, $50 \mathrm{~g}$ of herbal cannabis, $100 \mathrm{~g}$ of hemp plants - and up to $1 \mathrm{~kg}$ of khat (fines are also given for up to 10 times these amounts, so first possession of up to $10 \mathrm{~kg}$ of khat should see a fine of up to DKK 5000 - about EUR 670). In Lithuania, a 'small quantity' of cannabis plant is no more than $5 \mathrm{~g}$, but for khat the limit is $100 \mathrm{~g}$; and while a 'very large quantity' of cannabis plant is defined as over $2.5 \mathrm{~kg}$, for khat this figure is over $50 \mathrm{~kg} .{ }^{6}$

\section{Khat availability and use in Europe?}

\subsection{Khat use}

Two distinct groups of khat users exist in Europe. There is a growing interest in herbal and uncontrolled psychoactive substances among some young Europeans. This market is based around Internet suppliers as well as specialist shops found in some countries. Research into the availability of psychoactive substances on the Internet conducted by the EMCDDA has found that both khat and a range of synthetic cathinones are available to European consumers. While little is known about the scale of this market, it appears that khat is not among the most sought-after herbal substances available, and the number of regular consumers in this group is presumably very small. Khat use among first and second generation immigrant groups from countries in which khat use is common is likely be a greater issue. Khat chewing is practised in countries in East Africa (Ethiopia, Somalia, Kenyan, Eritrea, Djibouti, Tanzania, Uganda) and to some extent in the Arabian Peninsula (Yemen and Saudi Arabia) (UNODC, 2009a). As noted already questions on khat are not included as a standardised item in most adult or youth surveys conducted by EU Member States (EMCDDA, 2002). Nevertheless, khat use is sporadically reported in Europe as a substance of choice among immigrants from Somalia, Ethiopia, Kenya and Yemen (Klein et al., 2009). There are a few published studies of khat use by immigrant communities in European countries (ACMD, 2005). However, these have mostly been conducted in the UK, and it is unclear to what extent their findings can be assumed to reflect patterns of use elsewhere in Europe. Nonetheless, the studies available do point to significant levels of use within some communities. For example, Patel et al. (2008) found that in 2005, among the Somalis interviewed, $34 \%$ had used khat in the month prior to the interview although less than $4 \%$ reported using the drug on a daily basis; a figure similar to that found earlier among the London Somali refugee community (Griffiths et al., 1997). The

\footnotetext{
${ }^{4}$ Circular 1/1998 part II - Drug cases: the importance of quantity in the legal assessment and use of writs with the option of a fine.

5 Director of Public Prosecutions Notice 6/2006, revised September 2008.

6 Decree of the Minister of Health of the Republic of Lithuania regarding recommendation for the determination of small, large and very large quantities of narcotic and psychotropic substances no. V-239, 23 April 2003.
} 


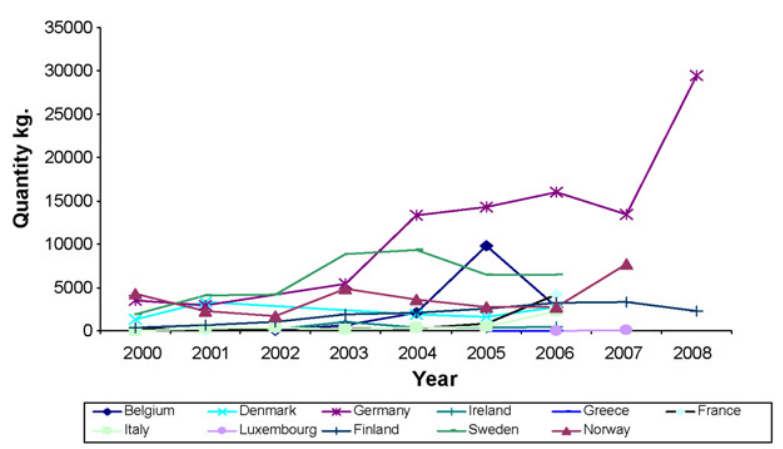

Sources: UNODC. 2000-2006 Annual Report Questionnaire. Data: last uploaded on 30/09/2008: EMCDDA. 2007-2008 from National Reports to the EMCDDA.

Fig. 2. Quantities of khat seizures by country and year in some EU Member States and Norway (2000-2008). Sources: UNODC: 2000-2006 Annual Report Questionnaire. Data: last uploaded on 30/09/2008; EMCDDA: 2007-2008 from National Reports to the EMCDDA.

Somali community in the UK is probably the most studied group in respect to the use of khat in Europe, and studies report estimates of current users ranging between 34\% and 67\% (ACMD, 2005). Studies generally report more use of the plant among males, generally in group settings. There may be a tendency to under-report khat use among women, which is a more stigmatised behaviour and more likely to occur at home or alone (ACMD, 2005; Buffin et al., 2009). Most studies have suggested that khat users are unlikely to use other psychoactive substances (ACMD, 2005) which distinguishes them from most other groups of recreational drug users in Europe, where polysubstance patterns are increasingly the norm. Use of khat among Somali communities has also been reported in Denmark (around 1350 users) and Sweden (2000-3000 users) (WHO Expert Committee on Drug Dependence, 2006).

\subsection{Khat seizures}

Interpreting drug seizure data is always difficult, however this is doubly so for substance like khat. As khat is not controlled in many European counties, it is particularly difficult to estimate the quantity of the substance available on the European drug market.

Global seizures of khat were estimated at 106.9, 97.5 and 101.4 tonnes in 2004, 2005 and 2006, respectively (UNODC, 2009b). Interestingly, if these estimates are accurate, Europe would account for around $40 \%$ of all seizures (UNODC, 2009b). Twelve of the 30 Member States reporting to the EMCDDA reported seizures of khat to the UNODC for the year 2006. In that year approximately 1300 seizures were made in those 12 countries, amounting to 41 tonnes of khat (Fig. 2), with Germany seizing by far the greatest amount of the drug at almost 16 tonnes, and Sweden the next greatest at approximately 6.5 tonnes (Fig. 2). More recent data is scarce; however, according to data reported to the EMCDDA, Norway seized almost 8 tonnes of khat in 2007, and Germany and Sweden seized approximately 30 and 11 tonnes respectively in 2008. In all three cases, the amounts are about twice the 2006 values (Fig. 2).

The importation of the khat plant is not controlled under drug legislation in the UK and the Netherlands. There is some information to suggest that there is substantial importation of the plant into these two countries. For example, there are reports that scheduled KLM flights are used to transit shipments of fresh khat from Nairobi to the UK (Carrier, 2007). Both countries serve their respective local markets and are used for transhipment to other European countries, Canada and the USA. Imports of the plant from Kenya, Ethiopia and Yemen into London airports in 2004 were estimated at 6 tonnes a week (Anderson et al., 2007), or over 300 tonnes a year. If this estimate remains accurate today, the volume of khat seized in Ger-

\section{Cathinone}<smiles>CC(N)C(=O)c1ccccc1</smiles>

Methcathinone<smiles>CNC(C)C(=O)c1ccccc1</smiles>

Amphetamine<smiles>CC(N)Cc1ccccc1</smiles>

\section{Mephedrone}<smiles>CNC(C)C(=O)c1ccc(C)cc1</smiles>

Fig. 3. Molecular structures of cathinone and amphetamine, methcathinone and mephedrone. Source: EMCDDA (2009c).

many in 2008 ( 30 tonnes) is equivalent to only $10 \%$ of the estimated amount imported annually into the UK.

Historically, East African countries and Yemen have been identified as major producers and consumers of khat, and these countries remain the main sources of the plant. Khat is imported into Europe and beyond primarily by air, in part necessitated by the short half-life of the plant's psychoactive ingredients. Canadian law enforcement authorities identify the UK as the primary transit country for shipment into Canada, with the Netherlands and Germany as the next most important; seizures were also made from flights originating in Belgium, France, Spain and Poland in 2007 (RCMP, 2005, 2006). This would suggest that a number of European countries are being used as transit points to the more lucrative North American markets, where khat is traded at prices around 6 times higher than in the UK (Klein et al., 2009).

\section{The chemistry of khat and its implications}

Although khat can be ingested as an infusion or smoked, by far the most common route of administration is to chew the plant ${ }^{7}$. Fresh vegetable material (stems, leaves and leaf buds) is chewed and the juice of the masticated material is swallowed, while the residues are spat out. Typically, an individual consumes 100-200 g of khat leaves ( 1 bundle) in a session, and its effects last for several hours. The stimulant effects of khat are due to its pharmacologically active ingredients - cathinone ${ }^{8}$ and cathine ${ }^{9}-$ which are naturally occurring alkaloids that can be extracted from the plant. Cathinone is absorbed through the buccal mucosa and the stomach. After absorption it is metabolically transformed, mainly to norephedrine (Feyissa and Kelly, 2008). Chemically, 'cathinones' are beta keto derivatives of phenethylamines, the group of chemical compounds that includes the amphetamines (the resemblance between cathinone and amphetamine is shown in Fig. 3).

Cathinone and cathine are usually present in khat at around $0.3-2 \%$ (King, 2009). In freshly cut leaves, cathinone is present at higher concentrations than cathine, but this changes over time as cathinone is enzymatically converted to cathine. While both of these substances are central nervous system (CNS) stimulants, cathinone is the more potent of the two (Fig. 4). A number of tech-

\footnotetext{
7 Drug profiles available online at http://www.emcdda.europa.eu/publications/ drug-profiles.

8 (S)-2-Aminopropiophenone, (-)- $\alpha$-aminopropiophenone or $S$-(-)-cathinone.

$9(+)-(R)-\alpha-[(R)-1$-aminoethyl]benzyl alcohol, or (+)-norpseudoephedrine.
} 


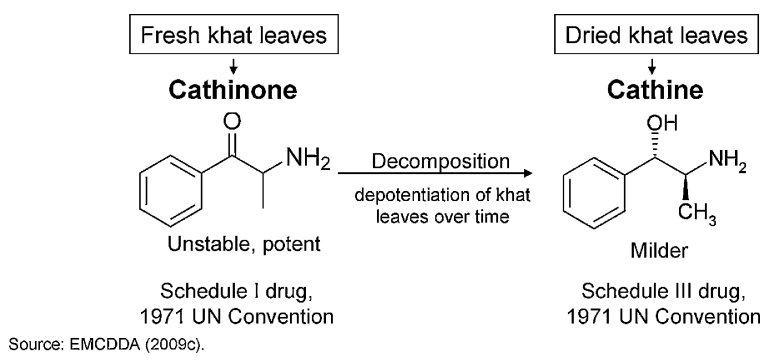

Fig. 4. The transformation of cathinone into cathine in the maturation process of khat. Source: EMCDDA (2009c).

niques are used to slow down this degradation process, for example wrapping the khat in banana leaves. However, as these techniques are not very effective, there is a strong incentive to bring the product quickly to its intended market.

Cathinone stimulates the central nervous system (CNS) by releasing dopamine, inhibiting dopamine and norepinephrine reuptake, and affecting the serotonin system (Ujvary, 2009). The pharmacological profile and sympathomimetic effects of cathinone, the main active principle of khat, are similar to those of amphetamine. Cathinone produces subjective effects similar to those of amphetamine, but with a lower potency: euphoria, increase in energy, cheerful mood, gaiety and talkativeness (Patel, 2000). Among the minor psychic adverse effects reported in Internet user forums ( such as Bluelight and Erowid ${ }^{10}$ ) and grey literature are: hyperactivity, insomnia, anxiety, irritability, agitation and aggression; short-lived psychoses have also been reported. Physical effects of khat include tachycardia (increased heart rate), anorexia (decreased appetite), and other alterations to the respiratory, gastrointestinal, hepatic, reproductive and central nervous systems (Cox and Rampes, 2003).

In the same way that amphetamine is the parent compound of the large phenethylamine family of stimulant, psychedelic, and entactogenic substances, cathinone forms the basis of a large series of synthetic derivatives. For example, methcathinone is structurally related to cathinone, like methamphetamine is related to amphetamine. Methcathinone ${ }^{11}$ is a psychoactive stimulant drug, which is internationally controlled under Schedule I of the 1971 UN Convention. It is usually snorted, but it can be also smoked, injected, or orally ingested. Methcathinone is a potent CNS stimulant and dopamine reuptake inhibitor.

\subsection{New synthetic 'designer' cathinones}

By the end of 2009, 15 cathinone derivatives have been reported to the European early-warning system (EWS). ${ }^{12}$ Of the 13 substances reported to the EWS in 2008, cathinones accounted for 6. Little evidence is available on the actual use of new synthetic cathinones other than some user reports and Internet accounts. These compounds produce stimulant effects and may have similar pharmacological profiles and health risks to the corresponding structurally related phenethylamines. ${ }^{13}$ However, being relatively

\footnotetext{
10 http://www.bluelight.ru/vb/home.php and http://www.erowid.org/.

11 ( \pm )-2-(Methylamino)-1-phenylpropan-1-one, ephedrone or M-CAT.

12 Methylone (bk-MDMA, MDMCAT, MDMC), MDPPP, MOPPP, MPHP, butylone (bk-MBDB, B1), MPPP, ethylone (bk-MDEA), ethylcathinone (ethylpropion), 3-fluoromethcathinone (3FMC), flephedrone (4-FMC, 4fluoromethcathinone), mephedrone (4-methylmethcathinone), MDPV (MDPK, 3,4-methylenedioxypyrovalerone), PPP ( $\alpha$-pyrrolidinopropiophenone), methedrone (bk-PMMA, 4-methoxymethcathinone, PMMC), metamfepramone (N,N-dimethylcathinone).

13 Drug profiles available online at http://www.emcdda.europa.eu/publications/ drug-profiles.
}

new research chemicals, no systematic research has been conducted on the toxicity or pharmacology of these substances, and the health risks and long-term effects (chronic toxicity) of these new drugs remain largely unknown (Wood et al., 2009).

Although there are reports that some cathinones are sold as 'ecstasy', they are also gaining importance as legal alternatives to controlled stimulants. There are indications of the existence of an end-user market that specifically seeks these 'legal highs', for which there is a growing awareness among recreational drug users. Recent reports to the EWS indicate that a number of synthetic cathinones, in particular mephedrone, have been identified in 'legal highs', advertised as 'bath salts', 'herbal bath salts' or 'plant food' and 'not for human consumption' and with no indication of the presence of psychoactive substances in the lists of ingredients.

\section{Conclusions: khat use today in Europe and potential issues for the future}

From a monitoring perspective, the information available on the use of substances like khat and more generally on patterns of substance use among minority populations in Europe remains inadequate. That said, examples of good practice do exist and a common feature of successful approaches, both in terms of research and service development, is that they are usually based on community engagement (Fountain et al., 2007). However, although excellent studies do exist, as well as some innovative methodological approaches to both accessing and working with minority communities, these are generally the exceptions rather than the rule. Across most of Europe patterns of drug use among minority populations are more a topic for speculation than science. Even given the difficulties of working in this area and the need to be sensitive to the possibility of inadvertently encouraging discrimination or the negative stereotyping of already vulnerable communities, this situation is not desirable. Without a good understanding of patterns of substance use within minority communities, appropriate service development will be hindered and important health and social needs will go unmet.

In the EU, although national drug policies are covered by the principle of subsidiarity, tensions are caused by a substance like khat, which is imported freely into some Member States and is subject to control and criminal sanction in others. To some extent there has been a general drift towards more common drug policies in Europe. To date, khat use has not figured prominently in the European policy debate. However, as seizures of the drug are increasing, it is not clear that this will continue, and it is possible that those countries that permit the importation and sale of khat may come under increasing pressure to review their regulation in this area. Moreover, important policy questions are raised by the fact that khat is controlled in some EU member states but not in others. Research in this area could profitably address the extent to which a ban has resulted in decreased consumption levels, as well as the relative costs and benefits to both immigrant and host communities of more punitive or more liberal approaches.

The chemistry of khat has important implications for the potential further diffusion of the drug in Europe and in part explains why currently khat consumption remains largely restricted to immigrant populations from areas where the behaviour is well established. The low concentration of active chemicals within the plant means that, compared to other stimulants, large volumes need to be consumed for users to achieve the desired typical dose. Drugs that are bulky are more difficult to conceal and transport. It is interesting to note, for example, that despite the far lower prevalence of use, by weight the current annual khat seizures in Europe are currently equivalent to about half the volume of the cocaine seizures. Moreover, although most drugs degrade over time, with 
khat the process is exceptionally rapid. The plant should ideally be consumed within a few days of harvesting. The route of administration for khat is also likely to result in a slow onset of stimulant effects. All these factors would tend to limit the potential of khat to become more popular within the large market for stimulant drugs in Europe. Put simply, a drug that is bulky, needs to be transported, sold and used quickly, and has an unfamiliar and inefficient route of administration, is not likely to be attractive to either illicit drug traffickers or consumers who have access to a wide range of other, more convenient alternatives. This is not the case for cathinone, however. This drug is a potent CNS stimulant and shares many similarities with amphetamine. Synthetic cathinones, therefore, can be regarded as having a significant potential for future diffusion. To some extent this appears to be happening, as cathinone-based drugs represent a growing proportion of the new psychoactive substances identified in Europe.

\section{Acknowledgements}

The authors would like to thank João Matias for his helpful contribution to the data analysis, Peter Fay for his comments on the text, and Michael Odenwald for his advice and support.

\section{References}

ACMD, 2005. Khat (Qat): assessment of risk to the individual and communities in the UK. Advisory Council on Misuse of Drugs (ACMD). Available at: http://drugs.homeoffice.gov.uk/publication-search/acmd/khatreport-2005/Khat_Report_2835.pdf?view=Binary (accessed 18-1-2010).

Anderson, D., Beckerleg, S., Hailu, D., Klein, A., 2007. The Khat Controversy - Stimulating the Debate on Drugs. Oxford, Berg.

Bergeron, H., Griffiths, P., 2006. Drifting towards a more common approach to a more common problem: epidemiology and the evolution of a European drug policy. In: Hughes, R., Lart, R., Higate, P. (Eds.), Drugs: Policy and Politics. Open University Press, pp. 113-124.

Buffin, J., Mir, Y., Mirza, I., 2009. Khat: current views from the community around the UK - findings from Community engagement forums. National drugs and race equality coalition. Available at: http://www.docstoc. com/docs/16231066/NDAREC-Khat-Report (accessed 18-1-2010).

Carrier, N., 2007. A strange drug in a strange land. In: Pieroni, A., Andebroek, I. (Eds.), Travelling Cultures and Plants: The Ethnobiology and Ethnopharmacy of Migrations. Berghahn Books, pp. 186-202.

Cox, G., Rampes, H., 2003. Adverse effects of khat: a review. Advances in Psychiatric Treatment 9, 456-463. Available at: http://apt.rcpsych.org/ cgi/content/full/9/6/456 (accessed 18-1-2010).

EMCDDA, 2002. Handbook for surveys on drug use among the general population. EMCDDA. Available at: http://www.emcdda.europa.eu/ html.cfm/index58052EN.html (accessed 18-1-2010).

EMCDDA, 2007. Early-warning system on new psychoactive substances - operating guidelines. European Monitoring Centre for Drugs and Drug Addiction, Lisbon. Available at: http://www.emcdda.europa.eu/themes/new-drugs/early-warning (accessed 18-1-2010).
EMCDDA, 2008. Monitoring the supply of heroin to Europe. EMCDDA. Available at: http://www.emcdda.europa.eu/publications/technical-datasheets/herointrafficking (accessed 18-1-2010).

EMCDDA, 2009a. 2009 Annual Report: the state of the drugs problem in Europe. EMCDDA, Luxembourg. Available at: http://www.emcdda. europa.eu/publications/annual-report/2009 (accessed 18-1-2010).

EMCDDA, 2009b. European Legal Database on Drugs (ELDD) - online database of information on European drugs-related legislation for the Member States and Norway. Available at: http://eldd.emcdda. europa.eu/html.cfm/index5036EN.html (accessed 18-1-2010).

EMCDDA, 2009c. Monitoring and reporting on the drug use in Europe; the EMCDDA perspective on khat. ESF-LiU Conference, the changing use and misuse of Catha edulis khat in a changing world, presentation given by Paul Griffiths, Likoping, Sweden, October 5-9, 2009.

Feyissa, A.M., Kelly, J.P., 2008. A review of the neuropharmacological properties of khat. Progress in Neuropsychopharmacology and Biological Psychiatry 32, 1147-1166.

Fountain, J., Patel, K., Buffin, J., 2007. Community engagement: the Centre for Ethnicity and Health model. In: Domenig, D., Fountain, J., Schatz, E., Bröring, G. (Eds.), Overcoming Barriers-Migration, Marginalisation and Access to Health and Social Services. Foundation Regenboog AMOC and Correlation Network, pp. 51-63. Available at: http://www.idpc.net/sites/default/ files/library/CORR_RP_OvercomingBarriers_EN.pdf (accessed 18-1-2010).

Griffiths, P., Gossop, M., Wickenden, S., Dunworth, J., Harris, K., Lloyd, C., 1997. A structural patter of drug use: Qat (khat) in the UK. British Journal of Psychiatry $170,281-284$

King, L.A., 2009. Forensic Chemistry of Substance Misuse. A Guide to Drug Control Cambridge. The Royal Society of Chemistry Publishing, Cambridge, UK.

Klein, A., Beckerleg, S., Hailu, D., 2009. Regulating khat - dilemmas and opportunities for the internal drug control system. International Journal of Drug Policies 20, 509-513.

Patel, N.B., 2000. Mechanism of action of cathinone: the active ingredient of khat (Catha edulis). East African Medical Journal 77, 329-332.

Patel, S.L., Wright, S., Gammampila, A., 2008. Khat use among Somalis in four English cities. Drugs: Education, Prevention and Policy 15, 37-53.

RCMP, 2005. Canada: drug situation report 2005. Available at: http://www.rcmpgrc.gc.ca/drugs-drogues/pdf/drug-drogue-situation-2005-eng.pdf (accessed 18-1-2010).

RCMP, 2006. Canada: drug situation report 2006. Available at: http://www.rcmpgrc.gc.ca/drugs-drogues/pdf/drug-drogue-situation-2006-eng.pdf (accessed 18-1-2010).

Ujvary, I., 2009. Overview of psychoactive plants. Personal communication presented at the 9th Annual Meeting of the REITOX Early Warning System Network, organised by the EMCDDA in Lisbon, 2009.

UNODC, 2009a. World drug report 2009. United Nation, Vienna. Available at: http://www.unodc.org/documents/wdr/WDR_2009/WDR2009_eng_web.pdf (accessed 18-1-2010).

UNODC, 2009b. Research Database, http://www.unodc.org/unodc/en/data-andanalysis/Research-Database.html?ref=menuside (accessed 18-1-2010).

WHO Expert Committee on Drug Dependence, 2006. 34th report (no. 942). WHO Geneva. Available at: http://whqlibdoc.who.int/trs/WHO_TRS_942_eng.pdf (accessed 18-1-2010).

Wood, D.M., Davies, S., Puchnarewicz, M., Button, J., Archer, R., Ramsey, J., Lee, T., Holt, D.W., Dargan, P.I., 2009. Recreational use of 4-methylmethcathinone (4-MMC) presenting with sympathomimetic toxicity and confirmed by toxicological screening. In: Abstracts of the 2009 North American Congress of Clinical Toxicology Annual Meeting, September 21-26, 2009, San Antonio, Texas, USA. Clinical Toxicology 47, 7, 733. 